Vol.7, No 1. Diciembre de 2015 pp. $181-207$

Recibido para publicación: 5 Septiembre de 2015.

Aceptado para publicación: 13 Noviembre de 2015

\title{
LAS INSTITUCIONES INVOLUCRADAS EN EL RÉGIMEN DE EXTRANJERÍA EN COLOMBIA, SU MARCO NORMATIVO Y FUNCIONES.
}

\author{
Institutions involved in the regime of foreigners in Colombia, its legal \\ regulatory and functions.
}

\author{
Autor: David Guerra Restrepo ${ }^{1}$ \\ Correspondencia: davidg.restrepo@gmail.com
}

\begin{abstract}
RESUMEN
El presente artículo de revisión corresponde a un segmento de la tesis de grado de la maestría en Migraciones Internacionales contemporáneas, promoción 2014, Universidad Pontificia de Comillas de Madrid. En este artículo se esbozará que todos los estados democráticos tienen la capacidad de decidir quienes entran y salen de tu territorio, basado en la soberanía que es uno de sus elementos básicos. En todos ellos existe el llamado régimen de extranjería que es el que está constituido por diferentes instituciones que son las encargadas de regular el flujo migratorio de los emigrantes e inmigrantes, necesiten o no visa, pero si obligatoriamente necesitan pasaporte, Colombia no es ajena a esta situación, y por ello hay dos instituciones que básicamente constituyen ese régimen. Así pues, este artículo tiene como finalidad estudiar estas instituciones, que en Colombia son básicamente dos: El Ministerio de Relaciones Exteriores y la Unidad Administrativa Especial Migración Colombia.
\end{abstract}

\section{Palabras Claves}

Emigración, inmigración, Migración, emigrante, migrante, pasaporte, visa, Estado de origen, Estado de destino, Control Migratorio, Verificación Migratoria.

\begin{abstract}
This article corresponds to a segment of the thesis of expertise in contemporary International Migration, 2014 promotion, Comillas University of Madrid. This article will outline all democratic states have the ability to decide who move in and out of your territory, based on sovereignty which is one of its basic elements. In all of them there is the so-called regime of foreigners which is what is constituted by different institutions that are responsible for regulating the migratory flow of migrants and immigrants, need or no visa, but if necessarily need a passport, Colombia is no stranger to this situation, and so there are basically two institutions that regime. Therefore, this article is to study these institutions, which in Colombia are basically two: The Ministry of Foreign Affairs and the Special Administrative Unit Colombia Migration.
\end{abstract}

\section{Keywords}

Emigration, immigration, migration, migrant, immigrant, passport, visa, rule of origin, country of destination, Immigration Control, Verification Immigration.

\footnotetext{
${ }^{1}$ Abogado, Universidad Simón Bolívar. Magister en Migraciones Internacionales Contemporáneas. Realizó judicatura en el Consulado General Central de Colombia en Nueva York, lugar en el que desarrollo diferentes funciones relacionadas con la deportación y extradición, fue calificado como el mejor judicante. Docente universitario en las asignaturas de Derechos Humanos y Derecho Internacional Humanitario (DIH) Artículo tomado de la tesis de maestría: "El régimen de extranjería en Colombia y sus Generalidades", del master Migraciones Internacionales contemporáneas, promoción 2014, Universidad Pontificia de Comillas de Madrid.
} 


\section{INTRODUCCIÓN.}

En el contexto colombiano el Ministerio de Relaciones Exteriores teniendo en cuenta el artículo (02) del Decreto 3355 de 2009, es el encargado de formular, planear, coordinar, ejecutar y evaluar la política exterior de Colombia, las relaciones internacionales y administrar el servicio exterior. Por esta razón, el Ministerio tiene funciones impuestas por el artículo 59 de la ley 489 de 1998, que son sus funciones generales como Ministerio y tiene las establecidas por el Presidente de la Republica mediante el artículo (03) del decreto 3355 de 2009, que modificó sus funciones internas propias de el, estas funciones internas quedaron establecida en (25) veinticinco funciones concretas, de las cuales la numero 17 expresa lo siguiente:

"Formular, orientar, ejecutar y evaluar la política migratoria de Colombia y otorgar las autorizaciones de ingreso de extranjeros al país, en coordinación con el Departamento Administrativo de Seguridad DAS"2

En este sentido es evidente que la política migratoria depende del Ministerio, esta política es desarrollada mediante una serie de programas que ejecuta en su mayoría el mismo ministerio y en otras se apoya de otras instituciones, por ejemplo el Programa Colombia nos Une, creado mediante la resolución 3131 de 2004. Este ha permitido que desde sus inicios exista un grupo o equipo destinado solo a que ejecute y desarrolle la política migratoria en busca del cumplimiento de protección y bienestar de todos los colombianos en el exterior. Este programa ha desarrollado varias iniciativas con el fin trabajar el tema migratorio teniendo en

${ }^{2}$ El Departamento Administrativo de Seguridad DAS, fue reemplazado por la Unidad Administrativa Especial Migración Colombia 
cuenta una visión global o integral, por ello se creó el plan comunidad, plan de retorno positivo, portal de redes Colombia y el observatorio de Migraciones.

Por otra parte existe una comisión creada para contribuir a la ejecución de la política migratoria del Estado, es la Comisión Intersectorial de Migración, esta fue creada mediante el decreto 1239 de 2003, es un órgano creado con la finalidad de ayudar a coordinar y orientar la ejecución de la política migratoria del país, hacen parte de esta comisión el Ministerio de Relaciones Exteriores quien lo preside mediante su Ministro, seguidamente el Ministerio de Defensa Nacional, Ministerio de Comercio Industria y Turismo, Planeación Nacional, instituto colombiano para el fomento de la educación superior "ICFES", Instituto Colombiano de Crédito Educativo y Estudios Técnicos en el Exterior "ICETEX", y el director de Director de Asuntos Consulares y Comunidades Colombianas en el Exterior del Ministerio de Relaciones Exteriores.

En este mismo sentido en Colombia existe un Sistema Nacional de Migraciones, aprobado en el año 2011, mediante la ley 1465 del 2011, y cuyo objeto está en el artículo segundo:

"Acompañar al Gobierno Nacional en el diseño y ejecución de políticas públicas, planes, programas, proyectos y otras acciones encaminadas al fortalecer los vínculos del Estado con las comunidades colombianas en el exterior."

Así mismo está conformado por la Comisión Nacional Intersectorial de Migraciones, mencionada anteriormente y quien es el eje central, seguidamente por las entidades estatales y gubernamentales, que no formen parte de la primera, pero que sus funciones y objetivos tengan o guarden relación con los temas concernientes a la emigración y la inmigración en Colombia; las comisiones 
Vol.7, No 1. Diciembre de 2015 pp. 181 -207

segundas del senado y la Cámara Representantes siendo que ambos cuerpos colegiados conforman el congreso de la Republica, la Mesa Nacional de la Sociedad Civil para las Migraciones, donde tienen participación el sector privado, las organizaciones no gubernamentales, la academia y las organizaciones de colombianos en el exterior cuyos objetivos atiendan temas migratorios. Vemos entonces que poco a poco empezamos a describir todo lo concerniente al régimen de extranjería en Colombia partiendo de la institución que es la encargada de formular la política migratoria.

\section{MÉTODOS}

El presente artículo se deriva de una investigación de tipo descriptiva, con un paradigma histórico hermenéutico. Se empleó el método deductivo. La técnica de recolección de información fue la revisión documental.

\section{RESULTADOS Y DISCUSIÓN}

De la revisión temática en torno al tópico migratorio se quiere destacar como resultados un aspecto muy importante y que merece atención porque es utilizado para prestar muchos servicios de migración propios del régimen de extranjería, este servicio es denominado, "Servicio Exterior de la República" el cual nos proponemos analizar:

\section{Servicio Exterior de la Republica}

Para entender que es el Servicio Exterior de la Republica, debemos ir a el artículo 3 del decreto 274 de 2000 , el cual lo define de la siguiente manera:

"La actividad administrada por el Ministerio de Relaciones Exteriores, en desarrollo de la política exterior de Colombia, dentro o fuera del territorio de la República, con 
el fin de representar los intereses del Estado $y$ de proteger $y$ asistir a sus nacionales en el exterior".

Existen aquí dos fines, el primero representar los intereses del Estado y la segunda, proteger y asistir a sus nacionales en el exterior, teniendo en cuenta que se desarrolla dentro y fuera del territorio, siempre en la prestación de esos servicios tratando de evitar la arbitrariedad - Según concepciones de arbitrariedad en Mejia Turizo \& Medina Solano (2014) - . Ahora bien, las instituciones encargadas de prestar esos servicios en el exterior son los Consulados y las Embajadas. La primera sigue las directrices de la Convención de Viena sobre Relaciones Consulares, en su artículo (5) cinco y aprobada en Colombia por la ley 17 de 1971 y la segunda, sigue las directrices de la Convención de Viena Sobre Relaciones Diplomáticas, aprobada por la ley 06 de 1972. Esta última tiene una función mucho más diplomática como su propio nombre lo indica, es decir, estrechar las buenas relaciones entre los Estados, mientras que en la primera, el Estado busca prestarle los servicios a sus nacionales cuando estos viven en otro Estado y en el lugar donde residen se encuentran bajo una jurisdicción consular de un consulado cercano. En un Estado receptor pueden existir varios Consulados, pero siempre existirá solamente una embajada. En el caso concreto de Colombia este tiene cincuenta y cinco embajadas (55), ciento nueve (109) Consulados y treinta y nueve (39) Consulados Ad Honorem distribuidos en los cinco continentes que cumplen las funciones antes mencionadas. Teniendo clara la diferencia entre los Consulados y las Embajadas, lo importante es describir claramente cuáles son esas funciones propias que realizan los Consulados en el exterior y cuales hace el Ministerio en el interior del territorio del Estado, como son muchas esas funciones, citaremos todas, pero profundizaremos en las que están directamente relacionadas con el fenómeno migratorio. Como lo expresamos anteriormente los Consulados son los encargados de ofrecerle servicios a los nacionales cuando estos residen en un Estado en el cual no son nacionales, los servicios consulares, citando de ejemplo el Consulado de Colombia en Nueva York (https://nuevayork.consulado.gov.co/) son los siguientes: Expedición de cedulas de ciudadanía, tarjetas de Guerra Restrepo, David 
Vol.7, No 1. Diciembre de 2015 pp. 181 -207

identidad, libreta militar provisional, Registros civiles, 
Vol.7, No 1. Diciembre de 2015 pp. 181 -207

Registros de Matrimonio, certificaciones y constancias, reconocimiento de firma en documento privado, reconocimiento de firma para autorización de salida de menores, exhortos o despachos comisorios, adquisición, renuncia y recuperación de la nacionalidad colombiana, solicitud de pasaporte y solicitudes de visas. Haremos énfasis en los tres últimos porque son los que están directamente relacionados con el régimen de extranjería.

\section{Nacionalidad Colombiana}

La Constitución Política de 1991, establece que son nacionales colombianos:

\section{Por nacimiento:}

a. "Los naturales de Colombia, con una de dos condiciones: que el padre o la madre hayan sido naturales o nacionales colombianos o que, siendo hijos de extranjeros, alguno de sus padres estuviere domiciliado en la República en el momento del nacimiento. b. Los hijos de padre o madre colombianos que hubieren nacido en tierra extranjera y luego se domiciliaren en territorio colombiano o registraren en una oficina consular de la República. Ningún colombiano por nacimiento podrá ser privado de su nacionalidad. La calidad de nacional colombiano no se pierde por el hecho de adquirir otra nacionalidad. Los nacionales por adopción no estarán obligados a renunciar a su nacionalidad de origen 0 adopción. Quienes hayan renunciado a la nacionalidad colombiana podrán recobrarla con arreglo a la ley".

Como es evidente la Constitución de 1991, creo unos cambios muy importantes en los derechos otorgados a los colombianos que residen en el exterior, por ejemplo, la nacionalidad para hijos de colombianos nacidos fuera del país; el mantenimiento de la condición de colombiano al adquirir otra nacionalidad; el anterior fenómeno obedecía porque la constitución de 1886 no le permitía a un colombiano tener una nacionalidad adicional a la colombiana, si quería tener otra nacionalidad debía renunciar a la de su país de origen, este fenómeno de prohibición llevó primero 
Vol.7, No 1. Diciembre de 2015 pp. $181-207$

que todo a que muchos colombianos renunciaran a su nacionalidad de origen para poder adquirir otra nacionalidad, esa renuncia la hacían en los consulados cuando residían en el extranjero; posteriormente a la promulgación de la constitución de 1991, la mayoría de esos colombianos se acercaban a los diferentes consulados y solicitaban la recuperación de la nacionalidad. Las normas que regulan todo lo relacionado con la adquisición, renuncia, perdida y recuperación de la nacionalidad colombiana es la ley 43 de 1993, el decreto reglamentario 1869 de 1994, el decreto 207 de 1993 en lo relativo a la recuperación de la nacionalidad colombiana. Es importante destacar que existe un convenio de nacionalidad celebrado entre Colombia y España y aprobado en Colombia mediante la ley 71 de 1979 cuyo propósito es la adquisición de la nacionalidad para ambos nacionales de estos Estados, el artículo primero de este convenio expresa:

'Los españoles de origen podrán adquirir la nacionalidad colombiana y los colombianos por nacimiento podrán adquirir la nacionalidad española cuando hayan estado domiciliados en el territorio del otro Estado por un plazo no menor de dos años cumpliendo los requisitos que determine la legislación del país cuya nacionalidad adquieran e inscribiéndose en los Registros que dicha legislación establezca o tenga establecidos, y siempre bajo el principio de reciprocidad respecto del plazo exigido y demás requisitos esenciales de la adquisición."

Este convenio a parte de la ley 71 de 1979, tiene en Colombia el decreto reglamentario 3541 de 1980, aparte de lo anterior este convenio tiene un protocolo adicional el cual fue aprobado en Colombia mediante la ley 638 de 2001 y tanto la ley como el protocolo fueron declarados exequibles por la corte constitucional mediante la sentencia C-915 de 2001.

\section{Los Pasaportes}

El decreto 1514 de 2012 por medio del cual se reglamenta la expedición de documentos de viaje colombianos, expresa: 


\section{Vol.7, No 1. Diciembre de 2015 pp. 181 -207}

"El pasaporte es el documento de viaje que identifica a los colombianos en el exterior. Por lo tanto, todo colombiano que viaje fuera del país deberá estar provisto de un pasaporte valido, sin perjuicio, de lo dispuesto en los tratados e instrumentos internacionales vigente."

Queda claro la importancia de este documento y sus efectos.

\section{Clases de pasaporte en Colombia}

El mismo decreto 1514 de 2012 establece seis (6) clases de pasaportes en Colombia, que son de obligatorio cumplimiento bajo sus propios requisitos, circunstancias y condiciones, son los siguientes:

\begin{tabular}{|c|c|c|c|}
\hline Clase de pasaporte & $\begin{array}{l}\text { Tiempo } \\
\text { de } \\
\text { vigencia }\end{array}$ & $\begin{array}{l}\text { Numero de } \\
\text { hojas }\end{array}$ & Órgano que lo expide \\
\hline Ordinario & 10 & 32 & $\begin{array}{l}\text { Ministerio de Relaciones, } \\
\text { Gobernaciones y } \\
\text { consulados. }\end{array}$ \\
\hline Ejecutivo & 10 & 48 & $\begin{array}{l}\text { Ministerio de Relaciones } \\
\text { Exteriores, Misiones } \\
\text { diplomáticas y consulados }\end{array}$ \\
\hline Fronterizo & 10 & 28 & $\begin{array}{l}\text { Misiones diplomáticas y } \\
\text { Consulados. }\end{array}$ \\
\hline Emergencia & 7 & 8 & $\begin{array}{c}\text { Ministerio de Relaciones } \\
\text { Exteriores, Misiones } \\
\text { Diplomáticas y Consulados. }\end{array}$ \\
\hline Exento & 30 & 1 & $\begin{array}{l}\text { Misiones diplomáticas y } \\
\text { consulados en el exterior }\end{array}$ \\
\hline
\end{tabular}




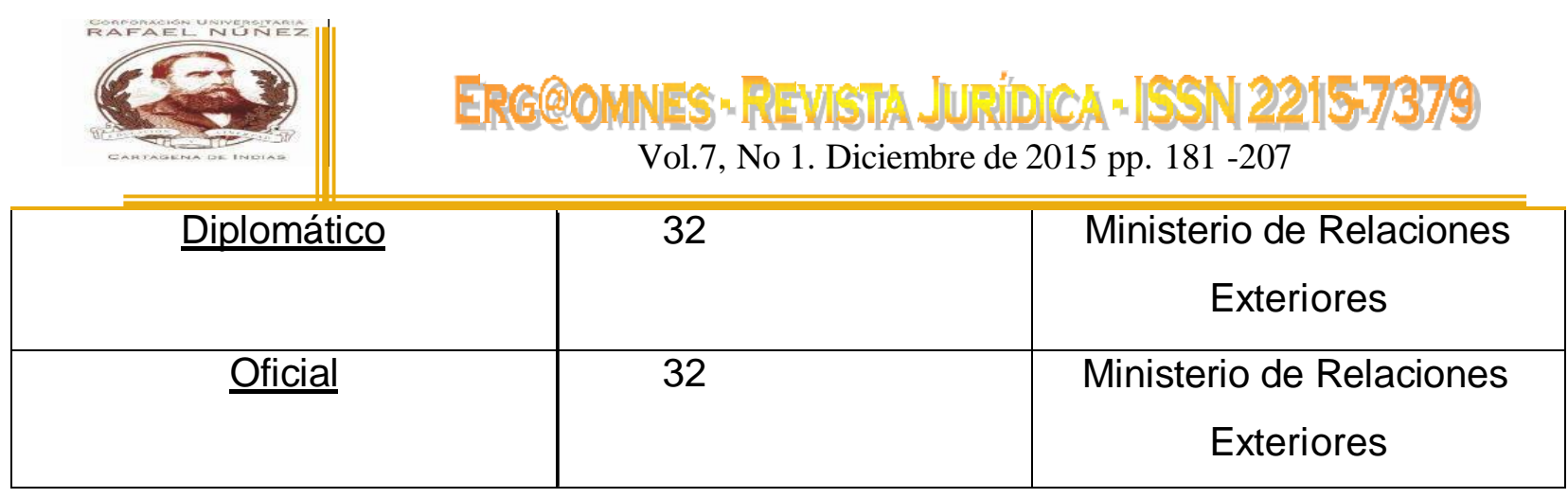

A excepción del pasaporte diplomático y el oficial que están regidos por el decreto 2877 de 2001, todos los demás se encuentran regulados por el decreto 1514 de 2012 anteriormente mencionado.

El pasaporte ordinario como si nombre lo indica es de uso de los nacionales ordinario; el fronterizo son para los nacionales que residen cerca de las fronteras con otros Estados, en este caso con Ecuador, Panamá, Venezuela y Brasil; el de emergencia se utiliza cuando un nacional que se encuentra en territorio de un Estado extranjero, infortunadamente se encuentra en alguna circunstancia de urgencia, por ejemplo la pérdida de su pasaporte ordinario, bajo tal circunstancia procede el pasaporte de emergencia; el exento procede cuando un nacional se encuentra fuera de estatus migratorio en otro Estado y por ello será deportado, expulsado o repatriado; el diplomático es el utilizado por el presidente de la república, sus ministros, directores de departamentos etc.; y el oficial es utilizado por los senadores, representantes a la cámara etc. Es importante resaltar que en Colombia hasta hace unos años no existía el pasaporte de lectura mecánica, este fue incluido en Colombia por el documento 9303 concretamente en su volumen 1 parte 1, de la Organización de Aviación Civil Internacional de sigla (OACl), porque Colombia se adhirió al convenio de Chicago mediante la ley 12 de 1947.

\section{La visa}

El artículo 4 del decreto 0834 de 2013, define la visa como "la autorización concedida a un extranjero para el ingreso al territorio nacional otorgada por el Ministerio de Relaciones Exteriores." El paso siguiente a seguir es descubrir cuáles son las clases de visas que exige el Estado para ingresar y son los siguientes, considerando el artículo 5 del decreto 0834 de 2013: 
Vol.7, No 1. Diciembre de 2015 pp. 181 -207

\begin{tabular}{|c|c|}
\hline \multicolumn{2}{|c|}{ Clases } \\
\hline Negocios & NE \\
\hline Temporal & TP \\
\hline Residente & RE \\
\hline
\end{tabular}

Como podemos observar son tres las clases de visas que se pueden otorgar en Colombia cuya principal característica de cada una es la siguiente:

Visa de Negocios NE. Se otorga cuando el extranjero ingresa a Colombia con propósitos de negocios.

Visa Temporal TP. Esta visa se otorgara al extranjero que desee ingresar al país sin el ánimo de establecerse en él.

Visa de Residente RE. Esta se otorga al extranjero que desee ingresar al país con el ánimo de establecerse en él.

Estas visas procederán cuando el propósito del viaje de los extranjeros, sea un propósito concreto muy diferente a un viaje con fines de turismo, porque en este último caso para determinados extranjeros, no se necesita visa de turista para ingresar al territorio siempre y cuando su permanencia no exceda los 180 días. El tema de las visas será tratado en el siguiente capítulo, lo importante ahora es dejar claro el concepto y las clases de visas en Colombia.

Luego de dejar claro que es el Ministerio de Relaciones Exteriores el encargado de formular la política exterior, de la cual hace parte el servicio exterior de la república, así como la política migratoria, es importante dejar por sentado que no es el Ministerio quien directamente ejecuta esa política migratoria, es decir, no es el Ministerio quien se encarga de verificar los requisitos de entrada, permanencia y salida en los diferentes puertos de Colombia; ni quien se encarga de hacer las respectivas verificaciones migratorias, las sanciones económicas, deportaciones y 
Vol.7, No 1. Diciembre de 2015 pp. $181-207$

expulsiones; existe una institución encargada de esas funciones y es La Unidad Administrativa Especial Migración Colombia, (en adelante Migración Colombia).

\section{Unidad Administrativa Especial Migración Colombia}

Migración Colombia fue creada bajo el decreto 4062 de 2011, concretamente en el artículo primero:

"Créase la Unidad Administrativa Especial, como un organismo civil de seguridad, denominada Migración Colombia, con personería jurídica, autonomía administrativa, financiera y patrimonio independiente, con jurisdicción en todo el territorio nacional, adscrita al Ministerio de Relaciones Exteriores."

En su parte motiva del decreto y en el artículo tercero (3) del mismo, ambos expresan el objetivo de Migración Colombia, el cual

Es ejercer las funciones de autoridad de vigilancia y control migratorio y de extranjería del Estado Colombiano, dentro del marco de la soberanía nacional y de conformidad con las leyes y la política que en la materia defina el Gobierno Nacional.

Esta es la institución encargada de ejecutar la política migratoria, (ver video institucional: https://www.youtube.com/watch?v=7r-Zy_D7Tr4) en el territorio de Colombia, como bien lo expresa el numeral primero del artículo 4 del decreto 4062 de 2011 donde están detalladas sus funciones:

1. Apoyar al Ministerio de Relaciones Exteriores y demás instituciones del Estado en la formulación y ejecución de la Política Migratoria.

De esta función se desprenden las demás funciones relacionadas con la ejecución de la política migratoria, las cuales son las funciones que se enuncian a continuación: 


\section{Vol.7, No 1. Diciembre de 2015 pp. 181 -207}

2. Ejercer la vigilancia y el control migratorio de nacionales y extranjeros en el territorio nacional.

3. Llevar el registro de identificación de extranjeros y efectuar en el territorio nacional la verificación migratoria de los mismos.

4. Ejercer funciones de Policía Judicial, en coordinación con la Fiscalía General de la Nación, para las actividades relacionadas con el Objetivo de la entidad, en los términos establecidos en la ley.

5. Capturar, registrar, procesar, administrar y analizar la información de carácter migratorio y de extranjería para la toma de decisiones y consolidación de políticas en esta materia.

6. Formular, dirigir, coordinar y evaluar los planes, programas y proyectos en materia de control migratorio, extranjería y verificación migratoria, en desarrollo y de conformidad con la política migratoria.

7. Expedir los documentos relacionados con cédulas de extranjería, salvoconductos y prórrogas de permanencia y salida del país, certificado de movimientos migratorios, permiso de ingreso, registro de extranjeros y los demás trámites y documentos relacionados con migración y extranjería que sean asignados a la entidad, dentro de la política que para tal efecto establezca el Gobierno Nacional.

8. Recaudar y administrar los recursos provenientes de la tasa que trata la Ley 961 de 2005 modificada por la Ley 1238 de 2008 y demás disposiciones que la modifiquen o adicionen. 
9. Recaudar y administrar las multas y sanciones económicas señaladas en el artículo $3^{\circ}$ de la Ley 15 de 1968, en el artículo 98 del Decreto 4000 de 2004 y demás disposiciones que la modifiquen o adicionen.

10. Coordinar el intercambio de información y cooperación con otros organismos nacionales e internacionales, bajo los lineamientos del Ministerio de Relaciones Exteriores y las demás entidades competentes.

11. Coordinar con el Ministerio de Relaciones Exteriores, la adopción y cumplimiento de los compromisos internacionales del Estado en materia migratoria.

12. Las demás que le sean asignadas.

Luego de observadas las funciones de migración Colombia, especialmente los numerales número uno (1), dos (2) seis (6), siete (7), ocho (8), nueve (9), podemos concluir que evidentemente es la encargada de ejercer la política migratoria en el país, desde ejercer control migratorio, verificación migratoria e incluso hasta ser policía judicial en colaboración con la Fiscalía General de la Nación. En ese orden de ideas, lógicamente primero es el control migratorio y después la verificación migratoria. Por otra parte es igualmente claro que depende totalmente del Ministerio de Relaciones Exteriores por cuanto está adscrita a ella, ejecutando solo funciones migratorias.

\section{Puestos de Controles Migratorios}

Varias de estas funciones que ejecuta migración Colombia, las ejecuta en los puestos de controles migratorios, ubicados en los distintos puertos, sean aéreos, terrestres, marítimos o fluviales, en los cuales se ejerce el control sobre los extranjeros que ingresan o salen del territorio nacional, y de igual forma para los nacionales Colombianos, para una mejor comprensión ilustraremos los diferentes 
Vol.7, No 1. Diciembre de 2015 pp. $181-207$

puertos, indicando el nombre del departamento, nombre de la ciudad, y el nombre del puerto:

\section{Puestos de Control Migratorios Aéreos Internacionales}

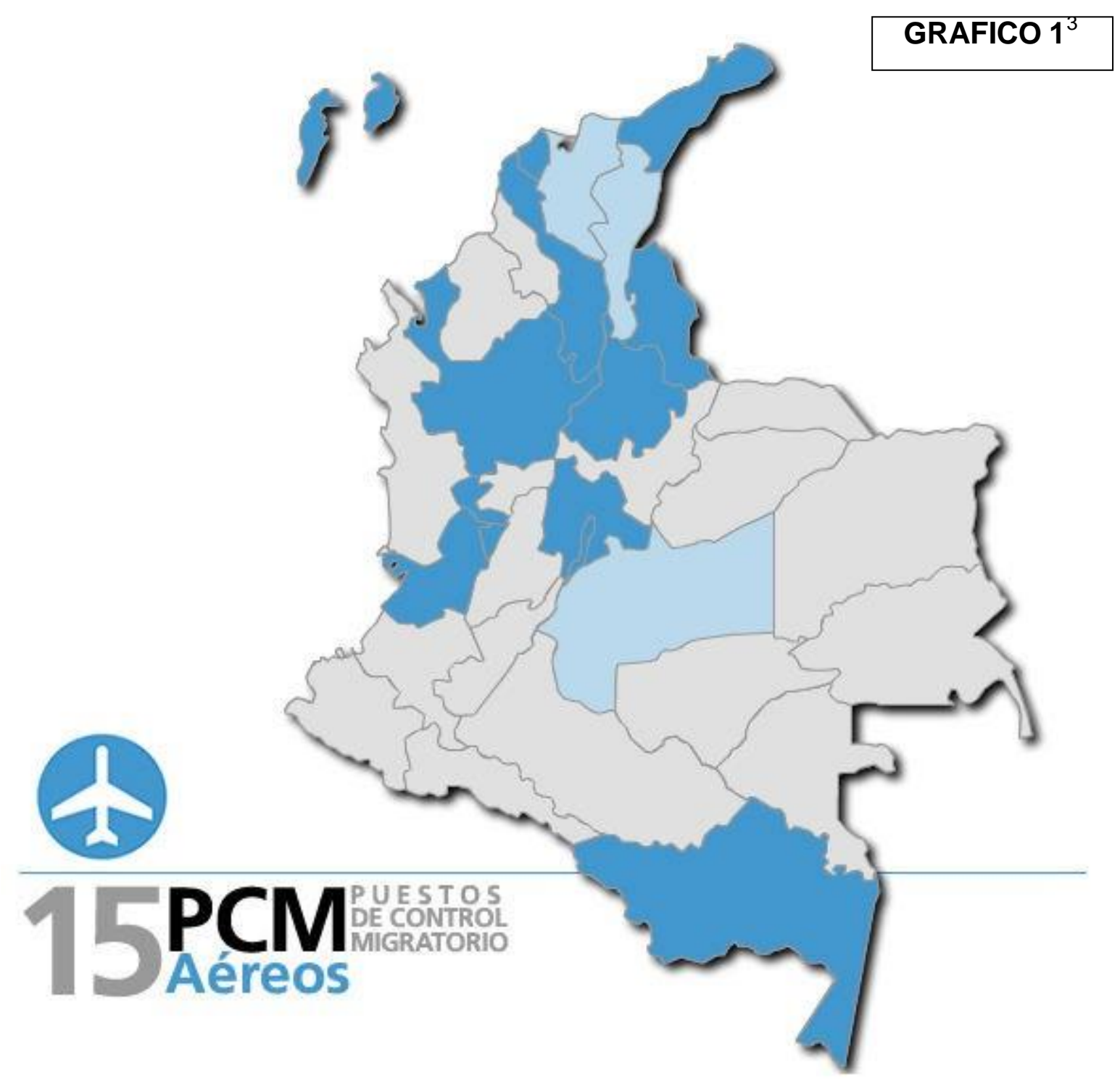

${ }^{3}$ Fuente Migración Colombia 
Considerando este mapa grafico de los puestos de control migratorio, a continuación citaremos los puestos concretos incluyendo el nombre del aeropuerto, son:

\begin{tabular}{|c|c|c|c|}
\hline $\begin{array}{c}\text { Bogota D.C. } \\
\text { El dorado }\end{array}$ & $\begin{array}{c}\text { Medellin } \\
\text { José Maria } \\
\text { Córdoba }\end{array}$ & $\begin{array}{c}\text { Barranquilla } \\
\text { Ernesto } \\
\text { Cortizzos }\end{array}$ & $\begin{array}{c}\text { Santa Marta } \\
\text { Simón Bolívar }\end{array}$ \\
\hline $\begin{array}{c}\text { Cartagena } \\
\text { Rafael Núñez }\end{array}$ & $\begin{array}{c}\text { Cali } \\
\text { Alfonso Bonilla }\end{array}$ & $\begin{array}{c}\text { San Andrés y P. } \\
\text { Gustavo Rojas }\end{array}$ & $\begin{array}{c}\text { Bucaramanga } \\
\text { Palonegro }\end{array}$ \\
\hline $\begin{array}{c}\text { Cúcuta } \\
\text { Camilo Daza }\end{array}$ & Pereira & Armenia & Leticia \\
Cúcuta & Eallecana & El Edén & Alfredo Vásquez \\
Camilo Daza & Alfonso López & & \\
\cline { 1 - 2 } & \multicolumn{2}{|c}{} \\
\cline { 1 - 2 }
\end{tabular}




\section{Puestos de Control Migratorios Marítimos}

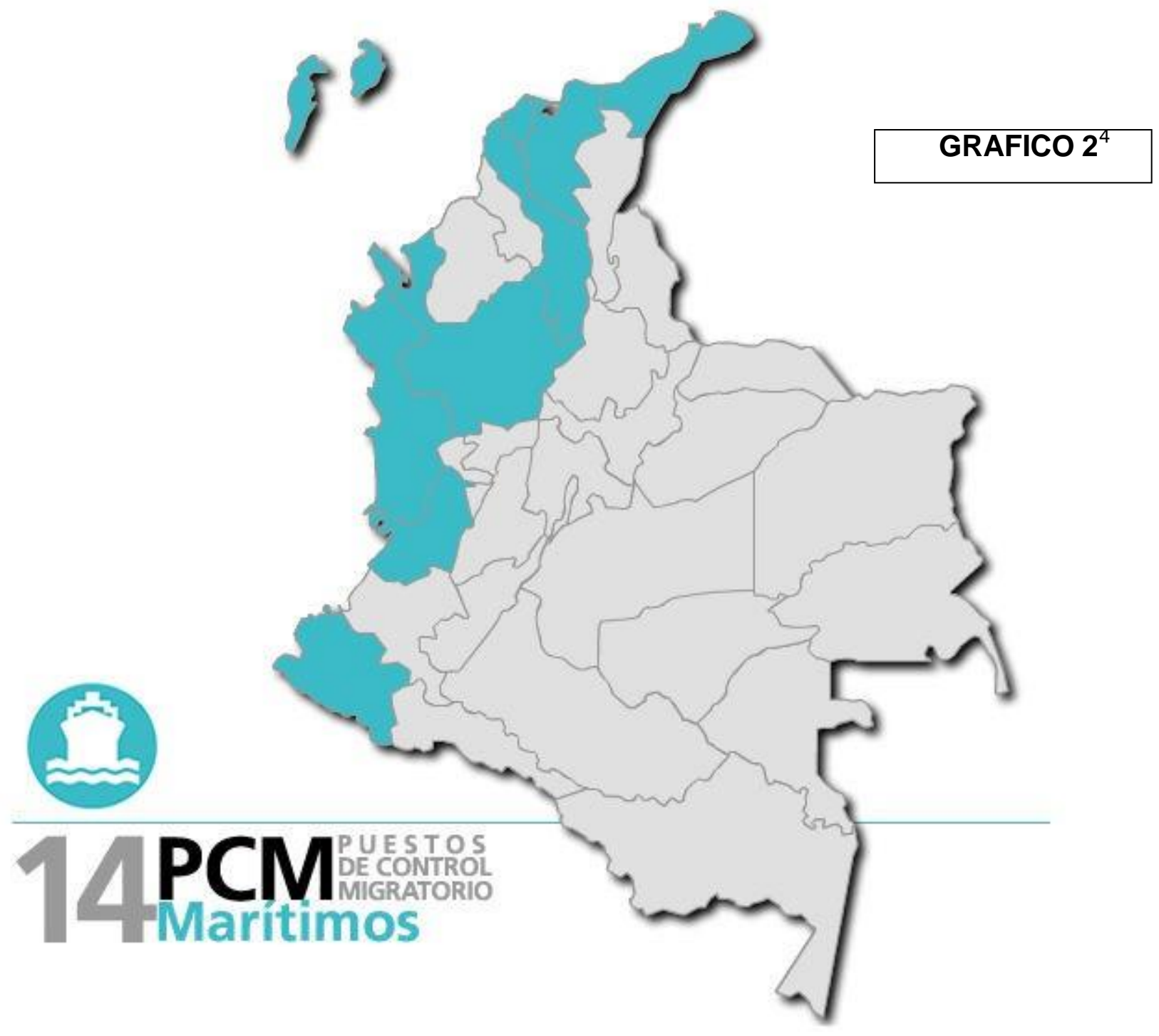

${ }^{4}$ Fuente Migración Colombia 
Vol.7, No 1. Diciembre de 2015 pp. 181 -207

Los puertos marítimos en Colombia son los siguientes:

\begin{tabular}{|c|c|c|}
\hline $\begin{array}{c}\text { Bahía Solano } \\
\text { (Chocó) }\end{array}$ & $\begin{array}{c}\text { Puerto de Barranquilla } \\
\text { (Atlántico) }\end{array}$ & $\begin{array}{c}\text { Puerto de Buenaventura } \\
\text { (Valle del Cauca) }\end{array}$ \\
\hline $\begin{array}{c}\text { Capurganá } \\
\text { (Chocó) }\end{array}$ & $\begin{array}{c}\text { Puerto de Cartagena } \\
\text { (Bolívar) }\end{array}$ & $\begin{array}{c}\text { Coveñas } \\
\text { (Sucre) }\end{array}$ \\
\hline Providencia & Puerto Nuevo & Puerto Simón Bolívar \\
(San Andrés Islas) & (Guajira) & (Guajira) \\
\hline San Andrés & $\begin{array}{c}\text { Puerto de Santa Marta } \\
\text { (San Andrés Islas) }\end{array}$ & (Magdalena) \\
\hline
\end{tabular}

Tumaco (Nariño) 


\section{Puestos de Control Miaratorios Terrestres}

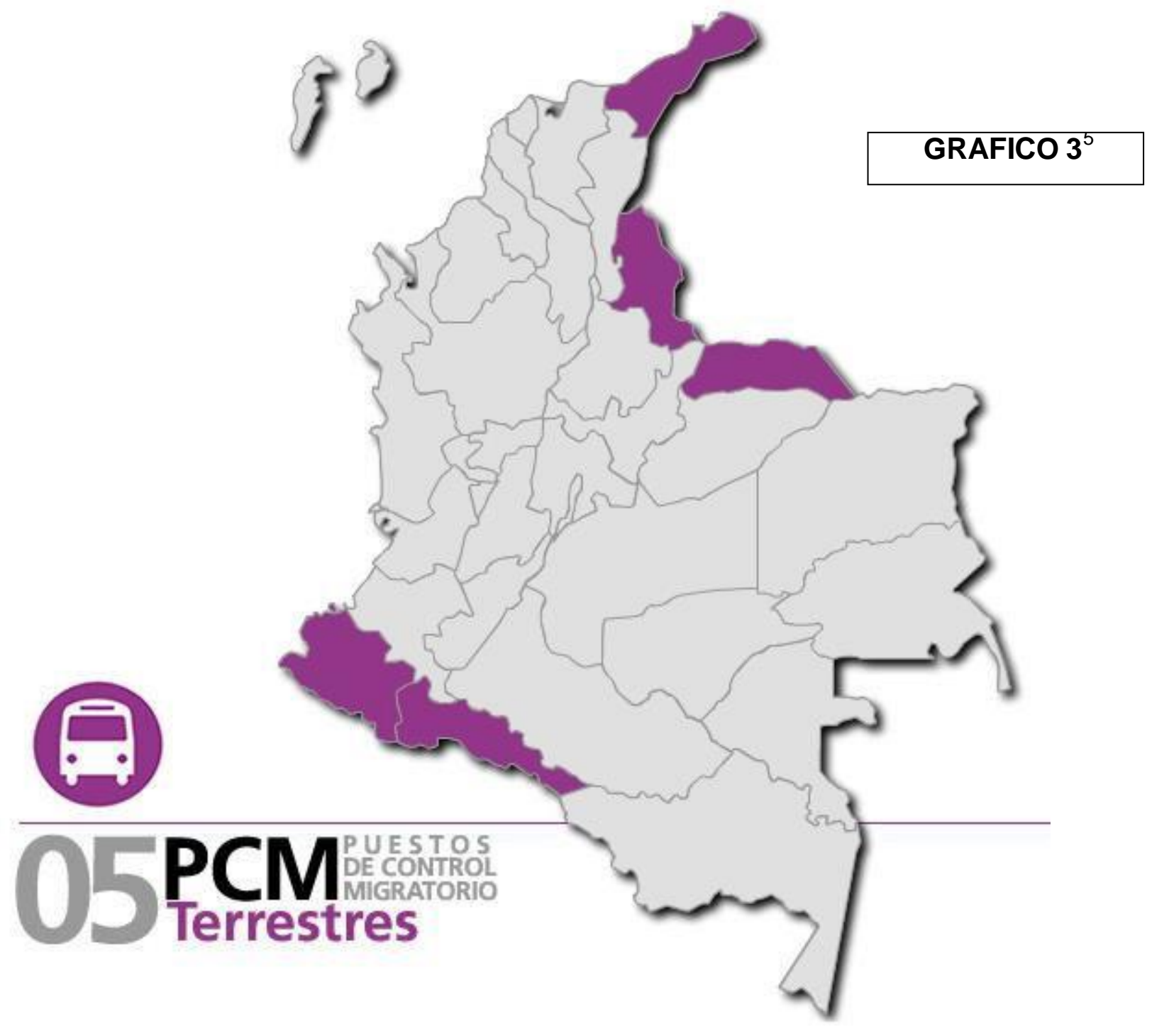

Los puestos de control migratorio terrestres en Colombia son los siguientes:

\begin{tabular}{|c|c|c|}
\hline $\begin{array}{c}\text { Puente internacional } \\
\text { José Antonio Páez } \\
\text { (Arauca) }\end{array}$ & $\begin{array}{c}\text { Paraguachón } \\
\text { (Maicao -La Guajira)V }\end{array}$ & $\begin{array}{c}\text { Puente Internacional Rumichaca } \\
\text { (Ipiales - Nariño) }\end{array}$ \\
\cline { 1 - 2 } Puente Internacional & Puente Internacional & \\
\cline { 1 - 2 } & &
\end{tabular}

\footnotetext{
${ }^{5}$ Fuente Migración Colombia
} 
Vol.7, No 1. Diciembre de 2015 pp. 181 -207

\begin{tabular}{|c|c|l|}
\hline $\begin{array}{c}\text { San Miguel } \\
\text { (Putumayo) }\end{array}$ & $\begin{array}{c}\text { Simón Bolívar } \\
\text { (Villa del Rosario }- \\
\text { Norte de Santander) }\end{array}$ & $\begin{array}{l}\text { Puestos de Control } \\
\text { Migratorios Fluviales }\end{array}$ \\
\hline
\end{tabular}

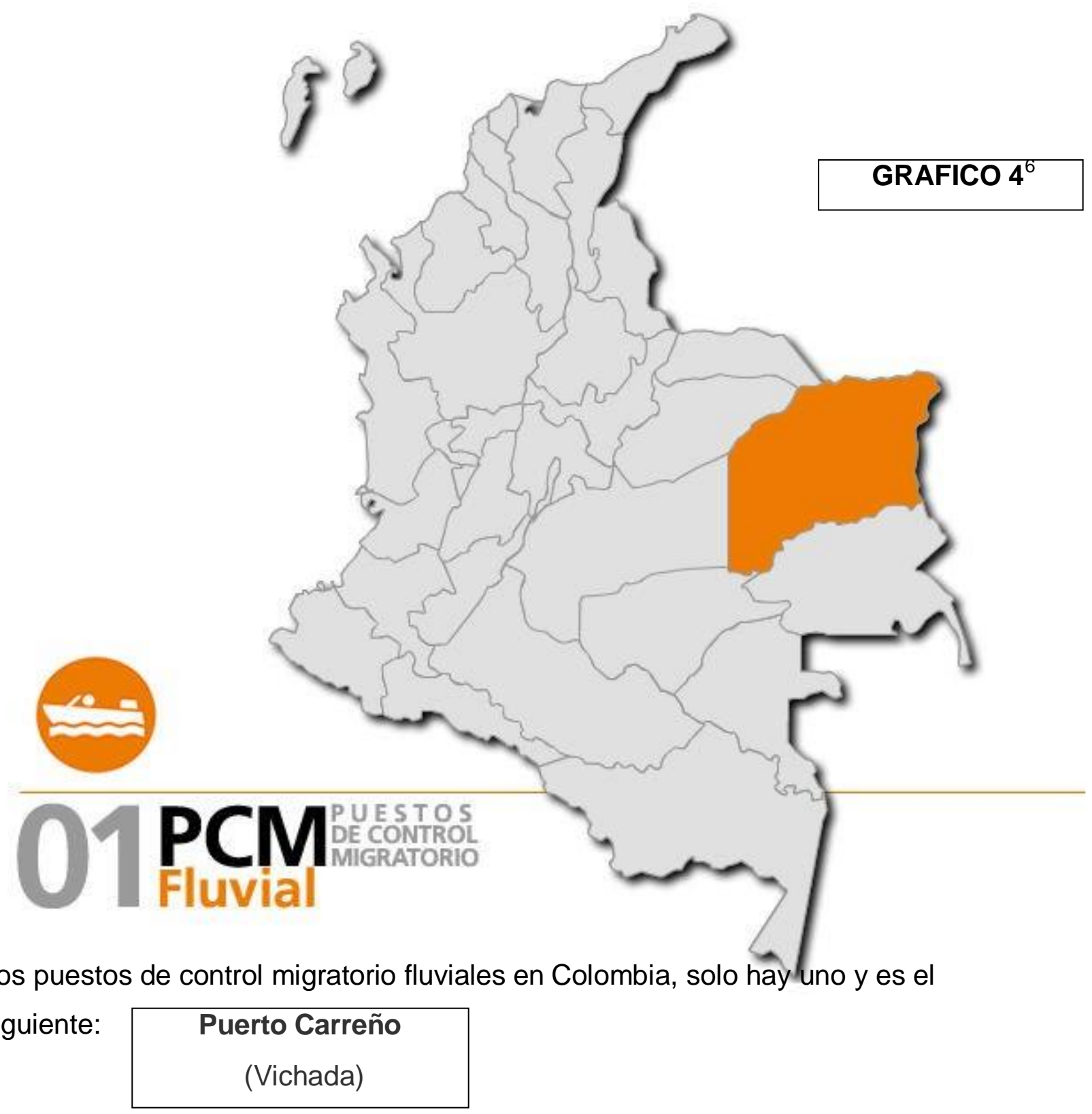

${ }^{6}$ Fuente Migración Colombia 


\section{Centros facilitadores de servicios Migratorios}

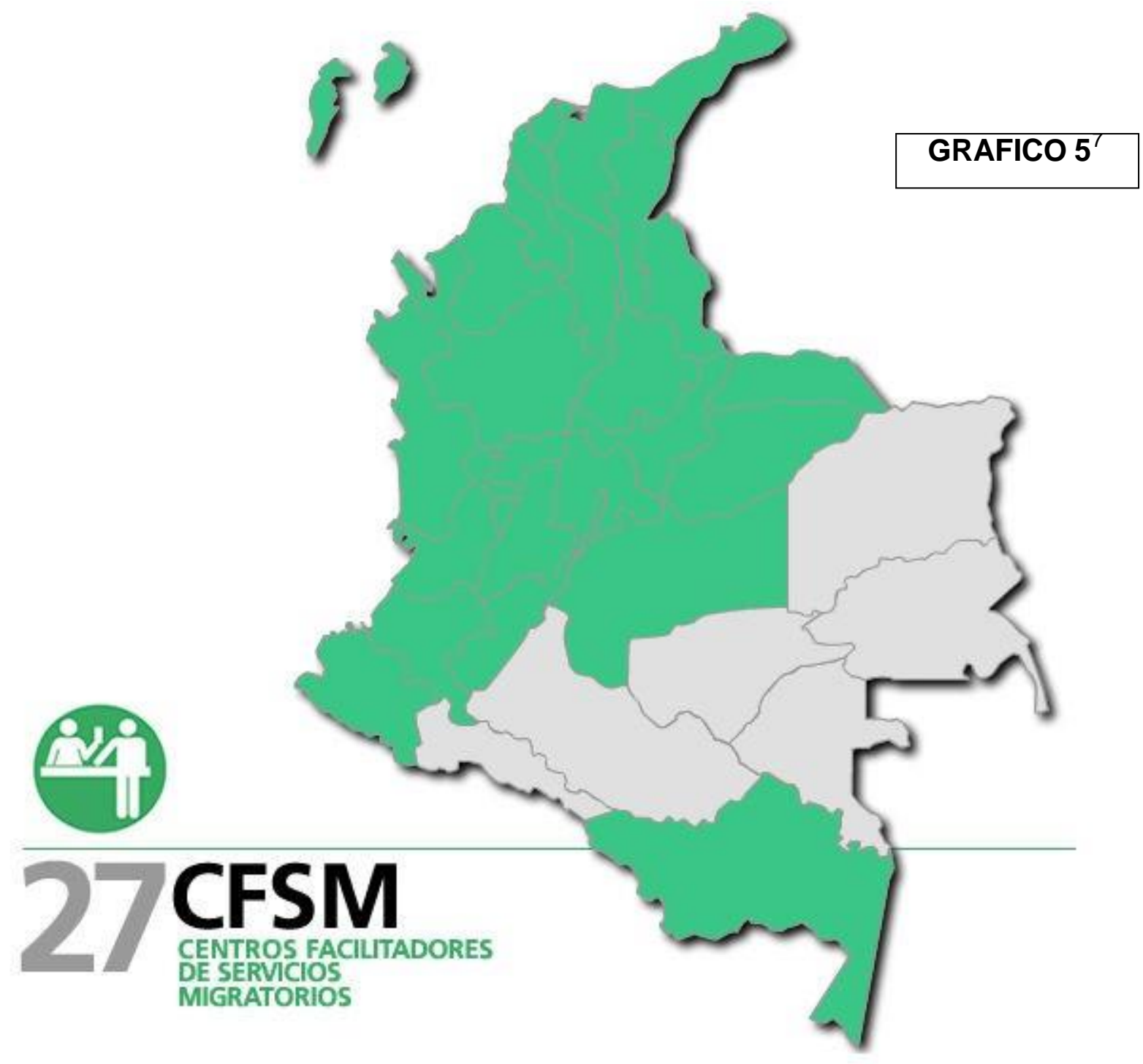

\begin{tabular}{|l|l|l|l|l|}
\hline 01. Riohacha & $\begin{array}{l}02 . \\
\text { Valledupar }\end{array}$ & 03. Barranquilla & 04. Montería & $\begin{array}{l}05 . \\
\text { Marta }\end{array}$ \\
\hline 06. Sincelejo & 07. Quibdó & 08.Bucaramanga & 09. Arauca & 10.Yopal \\
\hline
\end{tabular}

\footnotetext{
${ }^{7}$ Fuente Migración Colombia
} 


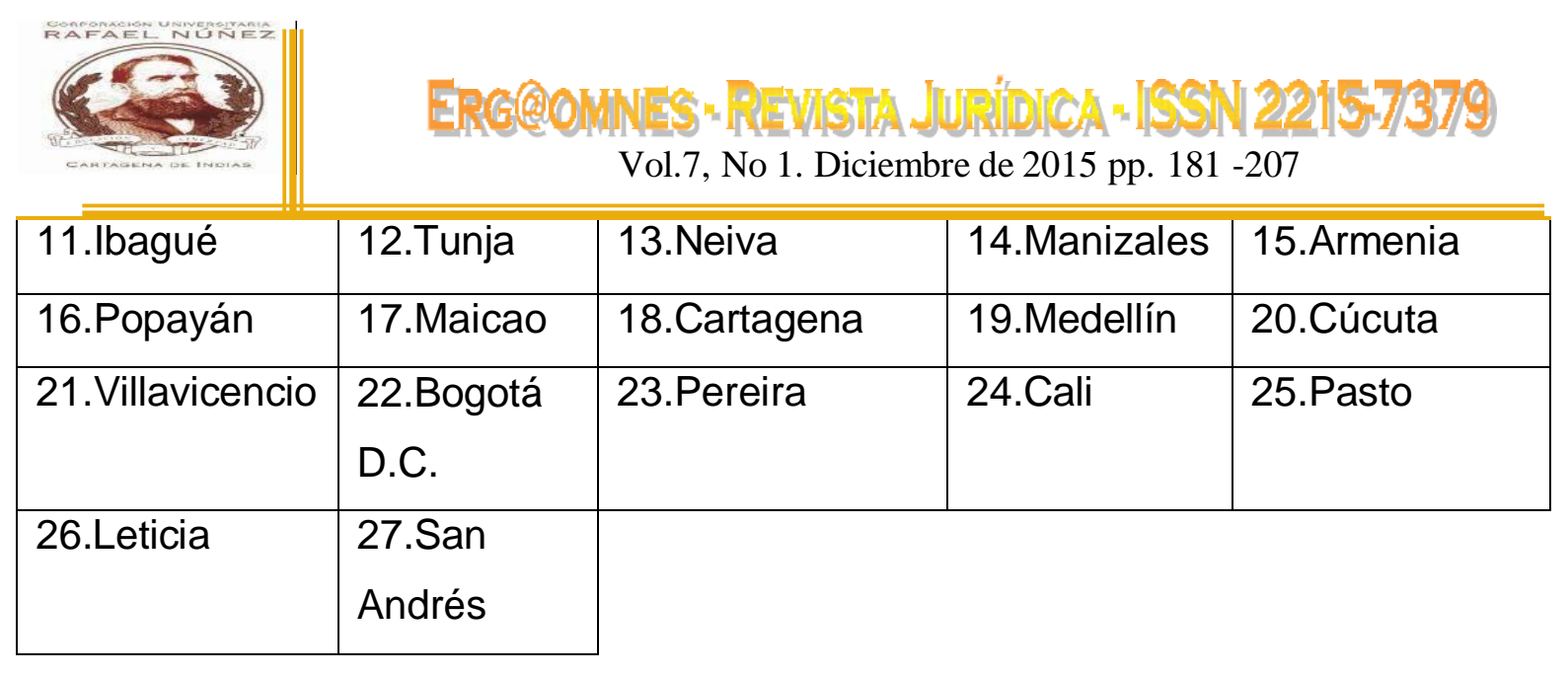

Según cifras del mes de enero de 2012, estos puestos de control migratorio establecidos en el territorio nacional, reportaron entre la suma de todos un total de 872.619 entradas y salidas de colombianos y extranjeros, de este consolidado el $82.54 \%$ es decir 720.228 registros correspondientes a puestos de control migratorios aéreos; el 15.64\% que comprende a 136.467 movimientos fueron en puestos de control terrestres: El valor restante que fue del $1.82 \%$ que es una suma de 15.924 flujos se presentó en los puestos de control marítimo y fluvial del país. En cuanto a la cantidad de extranjeros que ingresaron en ese mes, la cifra fue de 139.853, discriminados de la siguiente manera: El 15.4\% fueron estadounidenses, seguido por venezolanos con el $15.1 \%$, argentinos $8.4 \%$, brasileños $7 \%$, ecuatorianos $5.7 \%$. En cuanto a la salida de colombianos del territorio según el país de destino se tiene un total de 310.511 registros, los principales destinos fueron: Estados Unidos con un porcentaje de $25.8 \%$, Venezuela con un $17.1 \%$, Ecuador $11.5 \%$ y Panamá con un $11.2 \%$, de los principales destinos de los colombianos. (Migración Colombia) 


\section{CONCLUSIONES}

Las instituciones involucradas en el régimen de extranjería en Colombia, son: El Ministerio de Relaciones Exteriores, teniendo entre sus funciones la de formular, orientar, ejecutar y evaluar la política migratoria de Colombia y otorgar las autorizaciones de ingreso de extranjeros al país, en coordinación con la Unida Administrativa Especial Migración Colombia, quien es la encargada de ejercer las funciones de autoridad de vigilancia y control migratorio y de extranjería del Estado Colombiano, dentro del marco de la soberanía nacional y de conformidad con las leyes y la política que en la materia defina el Gobierno Nacional. Estas dos instituciones constituyen el régimen de extranjería en Colombia, la primera formula la política migratoria y la segunda es la encargada de ejecutarla.

\section{REFERENCIAS.}

\section{CONSTITUCIONES}

Colombia, Constitución Política de Colombia, artículo 96, Título III "De los Habitantes y del Territorio", Capítulo I "De la Nacionalidad".

\section{DECRETOS}

Decreto 3355 del 07 de septiembre de 2009, por medio del cual se modificó la estructura del Ministerio de Relaciones Exteriores y se dictaron otras disposiciones http://www.cancilleria.gov.co/sites/default/files/Normograma/docs/decreto_3355_2 009.htm 
Vol.7, No 1. Diciembre de 2015 pp. 181 -207

Decreto Reglamentario 1869 del 03 de agosto de 1994, por medio del cual se reglamenta la ley 43 de 1993.

Decreto 207 de 01 de febrero de 1993, por el cual se reglamenta la recuperación de la nacionalidad colombiana

Decreto 3541 del 26 de diciembre de 1980, por medio de la cual se reglamente la ley 71 de 1979, que aprueba el convenio de nacionalidad entre Colombia y España.

Decreto 274 del 22 de febrero de 2000, por el cual se regula el Servicio Exterior de la República y la Carrera Diplomática y Consular, http://www.diplomaticoscolombia.org/images/docs/274.pdf

Decreto 2877 del 24 de diciembre de 2001, por el cual se reglamenta la expedición de pasaportes Diplomáticos y Oficiales.

Decreto 1514 de 16 de Julio de 2012, por medio del cual se reglamenta la expedición de documentos de viaje colombianos y se dictan otras disposiciones.

Decreto 4060 del 31 de octubre de 2011, por medio del cual se crea la Unidad Administrativa Especial Migración Colombia, se establece su objetivo y estructura.

Decreto 0834 de 24 de abril de 2013, por medio del cual se establecen disposiciones en materia migratoria de la Republica. http://www.cancilleria.gov.co/sites/default/files/tramites_servicios/visas/archivos/de

decreto_834_del_24_de_abril_de_20131.pdf, Decreto 1239 del 20 de mayo de 2003, por medio del cual se creó la Comisión Nacional Intersectorial de Migración. 


\section{INSTITUCIONES}

Consulado General Central de Colombia en Nueva York https://nuevayork.consulado.gov.co/

El Departamento Administrativo de Seguridad DAS, fue reemplazado por la Unidad Administrativa Especial Migración Colombia

Ministerio de Relaciones Exteriores de Colombia https://tramites.cancilleria.gov.co/ciudadano/directorio/Misiones/enExterior.aspx Organización de Aviación Civil Internacional OACl http://www.icao.int/publications/Documents/9303_p3_v1_cons_es.pdf

\section{LEYES}

Ley 17 de 18 de noviembre de 1971. por la cual se aprueba la Convención de Viena sobre Relaciones Consulares, suscrita el 24 de abril de 1963. ftp://ftp.camara.gov.co/camara/basedoc/ley/1971/ley_0017_1971.html

Ley 06 del 15 de noviembre de 1972, por la cual se aprueba la "Convención de Viena sobre Relaciones Diplomáticas hecha en Viena el 18 de abril de 1961. ftp://ftp.camara.gov.co/camara/basedoc/ley/1972/ley_0006_1972.html

Ley 43 del 01 de febrero de 1993, por medio de la cual se establecen las normas relativas a la adquisición, renuncia, pérdida y recuperación de la nacionalidad colombiana; se desarrolla el numeral 07 del artículo 40 de la Constitución Política y se dictan otras disposiciones.

Ley 71 de diciembre 28 de 1979, por medio de la cual se aprueba el "Convenio de Nacionalidad entre Colombia y España", firmado en Madrid el 27 de junio de 1979. 
Vol.7, No 1. Diciembre de 2015 pp. $181-207$

Ley 638 del 04 de enero de 2001, por medio del cual se aprueban el "Protocolo adicional entre la República de Colombia y el Reino de España, modificando el Convenio de Nacionalidad del veintisiete (27) de junio de mil novecientos setenta y nueve (1979)", firmado en Santa Fe de Bogotá, D.C., el catorce (14) de septiembre de mil novecientos noventa y ocho (1998) y el "Canje de notas entre los dos Gobiernos que corrige el título y el primer párrafo del preámbulo del Protocolo", del veintisiete (27) de septiembre de mil novecientos noventa y nueve (1999).

Ley 1465 del 29 de junio de 2011, mediante la cual se creó el Sistema Nacional de Migraciones

Ley 12 del 23 de Octubre de 1947, Colombia aprobó su adhesión al Convenio Sobre Aviación Civil Internacional, suscrito en Chicago el 7 de Diciembre de 1944, comúnmente conocido como Convenio de Chicago, instrumento internacional que rige la aviación civil en el mundo..

Ley 15 del 23 de febrero de 1968, por la cual se concede una autorización al Gobierno Nacional para determinar por intermedio del Departamento Administrativo de Seguridad "DAS", nuevos modelos de cédulas de extranjería y certificados de conducta, y se establece el gravamen.

Ley 489 del 29 de diciembre de 1998, Por medio de la cual se dictan normas sobre la organización y funcionamiento de las entidades del orden nacional, se expiden las disposiciones, principios y reglas generales para el ejercicio de las atribuciones previstas en los numerales 15 y 16 del articulo 189 de la constitución $\begin{array}{lllll}\text { política } & y & \text { se } & \text { dictan } & \text { otras }\end{array}$ http://www.alcaldiabogota.gov.co/sisjur/normas/Norma1.jsp?i=186 
JURISPRUDENCIA

Sentencia C-915 de 2001, por medio de la cual se declara exequible la Ley 638 del 4 de enero de 2001, "por medio de la cual se aprueba el protocolo adicional entre la República de Colombia y el Reino de España modificando el Convenio de nacionalidad del (27) de Junio de mil novecientos setenta y nueve (1979), firmado en Santa Fé de Bogotá, D.C., el catorce (14) de septiembre de mil novecientos noventa y ocho (1998), y el Canje de notas entre los dos gobiernos que corrigen el título y el primer párrafo del preámbulo del protocolo, del veintisiete (27) de septiembre de mil novecientos noventa y nueve (1999)"

\section{VIDEOS}

Unidad Administrativa Especial Migración Colombia, ver video institucional https://www.youtube.com/watch?v=7r-Zy_D7Tr4

Unidad Administrativa Migración Colombia, video control migratorio: https://www.youtube.com/watch?v=5aOGTIPUu00

\section{DOCTRINA}

Mejia Turizo, Jorge \& Medina Solano, Stephanie (2014) Arbitrariedad en las decisiones judiciales y administrativas, Revista Jurídica Erg@omes, Vol. 6 Num 1. Diciembre 2014.

\section{IMAGENES}

Fuente

Imagen:

https://www.google.com.co/search?q=pasaportes\&biw=1366\&bih=643\&site=webh p\&source=Inms\&tbm=isch\&sa $=X \& e i=\mid p C S V a O G A 4 T Q s A X$ rolhg\&ved=0CAYQ_AU oAQ\#imgrc=SmSBgYTgQ1MNVM\%3A 